\title{
EFFECT OF ADMIXTURES ON SHRINKAGE PROPERTIES IN SELF COMPACTING CONCRETE
}

\author{
Saurav Kar ${ }^{1}$, Shreyasee Sulakshna Sanjay ${ }^{2}$ \\ ${ }^{1,2}$ M. Tech Student, School of Civil Engineering. KIIT University, Bhubaneswar, Odisha, India \\ Isauravrafa20@gmail.com \\ ${ }^{2}$ sulakshnasanjay@gmail.com
}

\begin{abstract}
With the rapid advancement in concrete technology, demand for sustainable building materials has increased manifold in last few decades. High strength concrete such as Self compacting concrete (SCC), also known as Self consolidated concrete, is considered one of the finest and highly modified concrete material. SCC represents a major evolution in the building industry. The increased use of SCC for construction and repair purposes lies in the fact that it is semi-flowable in nature and possess several advantages such as environmental, human, technological and economical. This paper mainly focuses on the effect of various shrinkage properties such as drying shrinkage, autogenous shrinkage and plastic shrinkage on performance of SCC. Detailed literature review suggests that early age shrinkage in SCC has been a major setback in attaining it's desired strength. Expansive cracking and capillary tension are considered as two main phenomena behind shrinkage in SCC. It is found out that factors like lower water/cement ratio or decreasing limestone filler/cement ratio leads to reduction in autogenous shrinkage. It is considered that cracks are one of the pivotal reasons behind the poor durability of concrete as they help in entering hazardous fluids. Hence cracks causes specific problems like plastic shrinkage. The effect of shrinkage reducing admixtures (SRA) on SCC was observed to be positive. SRA along with paraffin based curing compounds helps in reducing cracks. It was observed from rheological tests conducted on concrete as well as fresh SCC that, as far as drying shrinkage is concerned usage of SRA was found out to be effective while hydrophobizing admixtures tends to be useless. Along with addition of such admixtures, limestone fines in SCC mixes shows a reduction in autogenous shrinkage in SCC as compared to normal vibrated concrete (NVC). More importantly results show that total shrinkage in SCC mixed with limestone filler is slightly higher (not >9.2\%) than in NVC, while SCC made with viscous Modifying Agents (VMA) shows $7.7 \%$ less shrinkage than in NVC, due to lower autogenous and drying shrinkage.
\end{abstract}

Keywords: Admixtures, Capillary Tension, Cement/Binder Ratio, Cracking, Shrinkage, Viscous Modifying Agents.

\section{INTRODUCTION}

Self compacting concrete (SCC) is an innovative type of concrete developed in Japan. SCC does not require manual compaction and has enough mobility without aggregate segregation if dropped from a specified height. It has the filling capacity and the necessary fluidity required to flow through congested reinforcement detailing without sedimentation[1]. Owing to the fact that it does not require vibration to compact, it is very helpful in reducing the concrete placing costs, enhancement of working conditions and prevention of health hazards resulting from vibrations[2].

The mix proportioning and design of SCC needs to be highly precise so that it is able to achieve appropriate workability and enough mobility to flow under its own weight without segregation. This brings us to the disadvantages presented by SCC, particularly a higher shrinkage tendency as compared to normally vibrated concrete (NVC) also known as ordinary concrete (OC)[3]. Since shrinkage tends to present serviceability defects like cracking which may result in greater deformations than acceptable, it is a very important aspect to be researched and analyzed before standards are prepared. Usually shrinkage cracking is observed during the early stages of hydration[4][5]. There are mainly three types of shrinkages usually presented by SCC:-autogenous shrinkage (deformation of concrete without exchange of humidity with the surroundings), drying shrinkage (deformation of concrete due to humidity exchange between the porous structure and the surroundings) and plastic shrinkage[6]. Existing studies show that autogenous shrinkage of SCC happens to be lower than that of NVC whereas drying shrinkage is more significant for SCC than NVC. Generally proper curing is recommended to enhance shrinkage reducing effects along with chemical and mineral admixtures in definite proportions. Shrinkage reducing admixtures (SRA) have been found to be highly effective in counteracting shrinkage as it seems to reduce the surface tension of water in the capillary pores[6][2].

\section{BEHAVIOR OF SCC}

It is a well known fact that SCC can be used in slip form constructions such as slip form paving, owing to its self leveling, self flowing, and self consolidating nature [7]. Due to this ease SCC can be applied in smooth pavement construction with a high rate of production [8][14]. The slump value of this concrete generally varies from 254-330 $\mathrm{mm}$, or to be more precise $450-750 \mathrm{~mm}$ as in conventional SCC or semi-flowable SCC (SFSCC).As earlier stated 
autogenous shrinkage is a common factor concerning concrete, researchers have found out lower values of autogenous shrinkage in normal or ordinary concrete (CC) with values lower than $100 \mu$ strain. Normal concrete (bearing w/c ratio higher than 0.40 ) usually shows such results [9].

Scientists and researchers all over the world have proposed higher shrinkage for SCC for precast and prestressed concrete structures. Many investigations on SCC show that even though mechanical strength is superior to those of $\mathrm{CC}$ (Conventional Concrete),shrinkage properties remain a major drawback[10][27]. Shrinkage in SCC and OC were obtained 4\% and 6\% higher ACI 2009R (1997)[11]. The consolidation properties of SFSCC (Self Flowable SCC) were improved with the addition of chemical admixtures and fine materials. Along with the examining of the combined effects of drying shrinkage, fracture properties, creep and cracking potentials on SCC, few studies have also examined the free and restrained drying shrinkage properties, mechanical, fracture properties and creep coefficient in SFSCC mixes. The results were compared with conventional concrete mixes [12]. Experiments conducted under restrained conditions reveal that the cracking time of SFSCC mixes varied from 8-13 days, whereas CC mixes did not show any cracking till 28 days exposed to drying conditions [12]. Nowadays there are many methods to determine early shrinkage in concrete. Among them are RRTM (Restrained Ring Test Method) introduced by Carlson and Reading [13]. Wiegrink, Marikunte and Shah applied the same technology to find out the shrinkage cracking in high strength concrete [14].Further studies on drying and chemical shrinkage shows that volume of hardened concrete decreases with time. Tensile stresses develop in concrete as volume expansion is hindered. Hence structural members such as slabs and pavements are more prone to cracking. According to some researchers shrinkage in SCC is considered almost equal to OC (Ordinary Concrete) [15], while on the other hand international database shows that shrinkage in SCC is $10-15 \%$ higher than OC [16]. Knowing the fact that cracking in concrete occurs when it reaches the ultimate value of tensile strength (cracking resistance), according to Weiss and Berke [17], the cracking potential can be decreased by two methods : a.)Either by reducing the magnitude of stress development due to high deformation at later ages (due to drying shrinkage) or b.)Decreasing the rate of stress developmentwhen stress development is higher than cracking resistance at early ages while cracking resistance is higher than stress development at later ages.

\section{EFFECT OF ADDITIVE FILLERS ON SHRINKAGE PROPERTIES IN SCC}

Even though various modes of shrinkages in SCC are there, basically there are two important shrinkage propertiesautogenous shrinkage and drying shrinkage. Autogenous shrinkage basically refers to the deformation of concrete during its hydration process in adiabatic conditions, without allowing the exchange of temperature with the external environment [5]. Lower content of water cement ratio (w/c) conjugated with higher binder content leads to greater autogenous and drying shrinkage in structural detailing. This is because shrinkage is found to increase with the application of finely ground supplementary cementitious materials and filler employed in SCC [18]. Some standards such as ASTM C33, ASTM C989, EN-206 or EN-12620 specifies of Granulated Blast Furnace Slag (GBFS) can be used as an aggregate. Many researchers have experimented and obtained that replacing Granulated Blast Furnace Slag (GBFS) in place of sand has increased compressive strength in concrete. Scandiuzzi and Batttagin[19] obtained better long term strength due to hydraulicity of slag. While on the contrary Topcu and Bilir[20] have pointed out lower compressive strength, flexural strength and modulus of elasticity due to the high porosity of mixtures and reduced shrinkage in concrete.

When aggregates are partly replaced with slag having hydraulic capacity, it was found that concretes are susceptible to higher shrinkage because of volume reduction in cementitious materials(which occur during hydrationchemical shrinkage). It is well known that lower the w/c ratio greater is the shrinkage, when the water/binder ratio was kept well below 0.4 [21].Certain detailed studies show that only GBFS is not solely responsible in producing higher shrinkage[22].This phenomenon can be well explained as use of reaction with GBFS results in a C-S-H phase which means more tightly compacted pore networks. Arenallo et al.[23] have depicted out that packed dense slag-paste interfacial zone occurs because of blast furnace slag reactions[24].

As far as autogenous shrinkage is concerned, shrinkage strain and thermal strain are produced from the heat generated during the hydration process. Results obtained in favor of autogenous shrinkage are in accordance with other studies [25][26]. As the concrete specimen lose water and attain a constant equilibrium with outer environment, drying shrinkage reduces and attains a constant value. In the meantime autogenous shrinkage process goes on. With the passage of time (autogenous shrinkage/total shrinkage) ratio increases until it reaches a value of $68 \%-78 \%$. Some scientists[27][28]suggests that only increasing the quantity of limestone fillers and keeping water/cement ratio constant, have minor effect on autogenous shrinkage. Fig. 1 shows the variation of autogenous shrinkage with time.

Drying shrinkage cannot be directly measured. Few scientists have suggested that drying shrinkage can be obtained by subtracting autogenous shrinkage from total shrinkage, as recorded in Fig.2. Fig.3. shows higher the slag content, greater is the total shrinkage. 


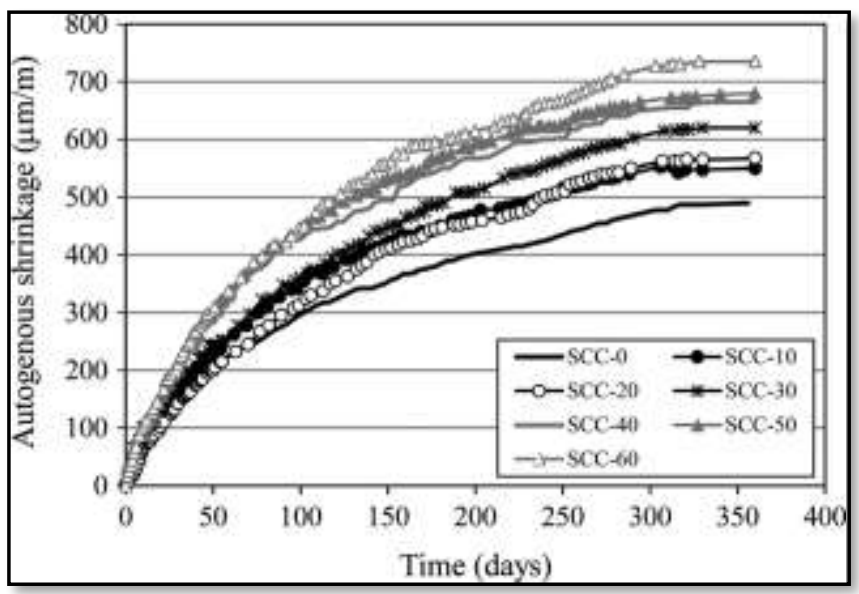

Fig-1: Autogenous Shrinkage vs. Time (days) [40].

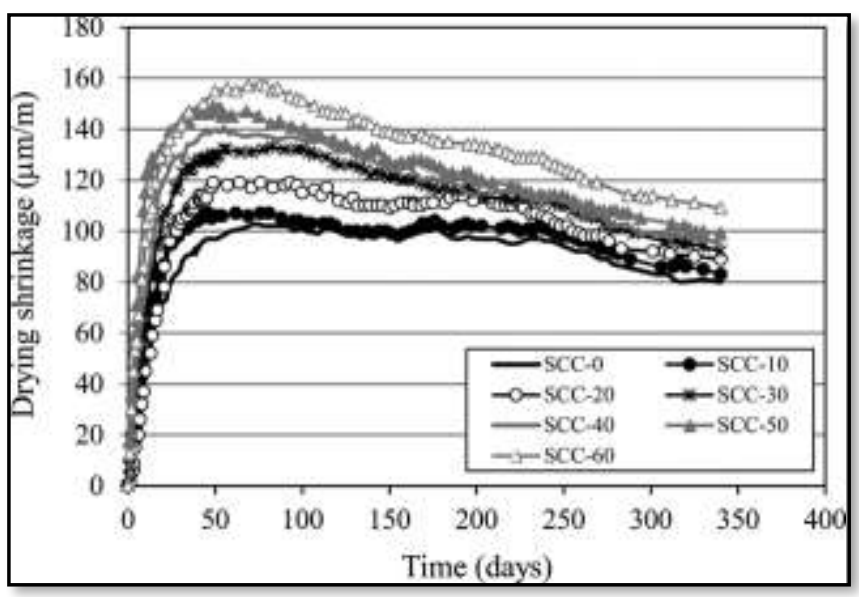

Fig-2: Drying Shrinkage vs. Time (days)[40].

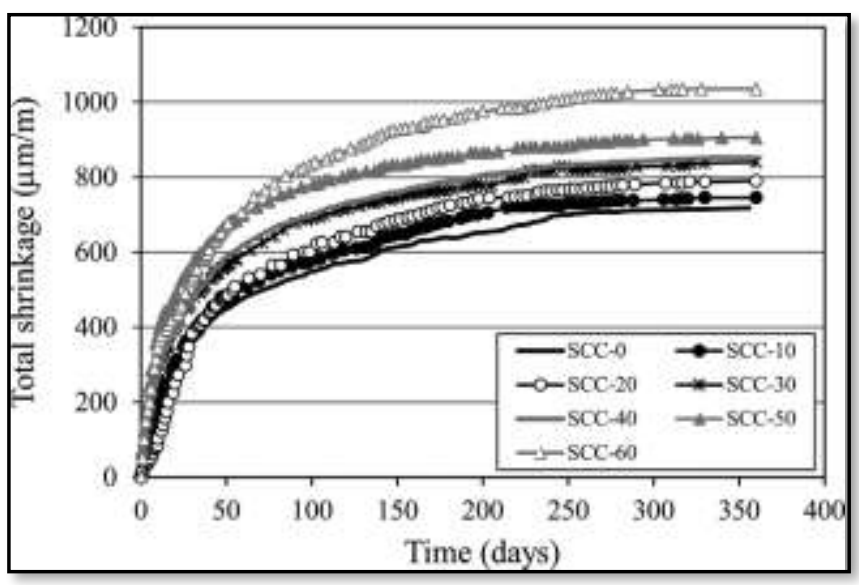

Fig-3: Total Shrinkage vs. Time (days)[40].

Higher fines and cement content and a higher paste volume are used in SCC than NVC (Normal Vibrated Concrete). Higher the paste volume, greater is the shrinkage [5]. However it should be noted that only significant increase in paste volume will not increase shrinkage, since other factors are also concerned like capillary pressure [29]. Shrinkage in SCC is retarded under the effect of many external additive fillers like silica fumes [30], flyash and limestone fillers. Similar to his previous works, Valcunde et al.[31]has also conducted experimental investigations to determine autogenous shrinkage in SCC with the application of limestone fillers. The $\mathrm{w} / \mathrm{c}$ ratio of the concrete mix kept well around 0.6.

In the experiment conducted [31], shrinkage in SCC was expected to be more than that in NVC, but things were very different. SCC presented less shrinkage values as compared with NVC. The reason behind this phenomenon can be attributed to the presence of limestone fillers. The calcium carbonate present in the limestone filler helps in reconversion of monosulfoaluminate to ettringite, which in turns increases the volume of hydrated phase[32]. Another reason proposed is that limestone filler being inert acts as normal aggregate, and hence hinders shrinkage.

\section{EFFECT OF ADMIXTURES \\ SUPERPLASTICIZERS ON SHRINKAGE}

AND

As earlier mentioned, admixtures helps in retarding shrinkage [31].To avoid risks of cracking in magnificent concrete buildings, $\mathrm{CaO}$ based expansive agent had been used in combination with SRA(Shrinkage Reducing Agents). This chemical product is based on calcium sulpho aluminates or $\mathrm{CaO}$ which reacts with water, to hinder expansion in reinforced concrete structures. Collepardi et al.[33]found out that $\mathrm{CaO}$ based expansive agent along with the combination of SRA produced a synergetic effect. The effect was helpful in expansion of concrete under wet curing also. SRAs are highly effective in retarding drying, autogenous and plastic shrinkage. The main mechanism behind this lies in the fact that concrete walls are subjected to lower surface tension. Usually under drying conditions, water from the pores of concrete tends to escape out, creating curved menisci. These curved menisci increases surface tension on the walls of pores. Under the effect of SRA, this effect gets highly reduced. Valeria Corinaldesi [34] has conducted a series of experiments to determine the advantages of using SRA in SCC. Results obtained report that addition of SRAs have proved effective in reducing drying shrinkage in concrete. The ultimate strain of "REF+SRA" mix was almost $40 \%$ less than the reference mix "REF". Sant et al. explained the presence of SRA caused portlandite oversaturation levels in solution. When calcium oxide was mixed with reference mix-"REF+CaO", initial expansion of $0.4 \mathrm{~mm} / \mathrm{m}$ reached a low value of drying shrinkage.VMA (Viscous Modifying Agents) have also shown a reduction in autogenous shrinkage in SCC.

\section{CONCLUSIONS}

In accordance to the review carried out, the following conclusions can be drawn

1. SCC and OC (Ordinary Concrete) have almost equivalent values of tensile strength and creep if compressive strength is held constant.SCC showed higher values of shrinkage than OC while elasticity modulus of SCC was negligibly small as compared to OC.SCC showed cracking at an earlier age as compared to OC. 
2. Autogenous shrinkage increases with decreasing water/cement ratio or aggregate/cement ratio and decrease in porosity.SCC has lower value of autogenous shrinkage and higher value of drying shrinkage as compared to OC.

3. Limestone fillers reduce the initial and final setting time in concrete. It causes a concrete block to shrink in water because water cannot enter the finer porous structure. Use of slag also has similar effect on the properties of SCC as it also results in higher fines content.

4. Shrinkage in SCC can be reduced by using SRA (Shrinkage Reducing Admixtures) and VMA (Viscous Modifying Agents).

5. SRAs prevent shrinkage cracking by reducing the surface tension of the pore water and limiting the development of capillary stresses and at the same time by reducing water evaporation from the concrete surface. It also lowers the restraint of the concrete when expansion occurs.

6. Drying shrinkage in SCC is also reduced by addition of SRA. SRA also happens to have other advantages like reducing deformations due to temperature stresses and increasing durability of concrete.

7. Higher values of paste volume and increase of water content in SCC results in a slightly lower value of compressive and flexural strength along with higher shrinkage cracking.

8. Effect of mineral fillers like limestone reduces initial and final setting times in SCC. Superplasticizers also respond differently to various filler thereby influencing the various properties of the given sample. However use of different fillers does not show significant differences in the porosity of the structure so there is not much difference in the final autogenous shrinkage.

\section{REFERENCES:}

[1]Domone P.L. "A review of hardened mechanical properties of self compacting concrete". Cement \& Concrete Composites 29 (2007) 1-12.

[2]Lino Maia , Helena Figueiras, Sandra Nunes , Miguel Azenha , Joaquim Figueiras . "Influence of Shrinkage Reducing admixtures on distinct SCC mix compositions". Construction and Building Materials 35 (2012) 304-312.

[3]Philippe Turcry, Ahmed Loukili, Khalil Haidar, Gilles Pijaudier-Cabot, and Abdeldjelil Belarbi. "Cracking Tendency of Self-Compacting Concrete Subjected to Restrained Shrinkage: Experimental Study and Modeling". J. Mater. Civ. Eng. 2006.18:46-54.

[4]Miguel José Oliveira, António Bettencourt Ribeiro , Fernando Garrido Branco "Curing effect in the shrinkage of a lower strength self-compacting concrete". Construction and Building Materials xxx (2015) .

[5]Amjad Alrifai, Salima Aggoun, Abdelkader Kadri, Said Kenai , El-hadj Kadri "Paste and mortar studies on the influence of mix design parameters on autogenous shrinkage of self-compacting concrete". Construction and Building Materials 47 (2013) 969-976.

[6]Andreas Leemann , Peter Nygaard , Pietro Lura. "Impact of admixtures on the plastic shrinkage cracking of selfcompacting concrete". Cement \& Concrete Composites 46 (2014) 1-7.

[7]Bonen, D., and Shah, S. P. (2005). "Fresh and hardened properties of self consolidating concrete.” Prog. Struct. Eng. Mater., 7(1), 14-26.

[8]Wang, K., Shah, S. P., and Voigt, T. (2010). "Selfconsolidating concrete for slip-form construction: Properties and test methods." The 50-year teaching and research anniversary of Prof. Sun Wei on advances in civil engineering materials, C. Miao, G. Ye, and H. Chen, eds., RILEM, Bagneux, France, 161-172.

[9]Davis, H.E., 1940. Autogenous Volume Change of Concrete. Proceedings, 43rd Annual American Society for Testing Materials Meeting, Atlantic City, NJ, p.1103-1113.

[10]Bissonnette, B., Pierre, P., and Pigeon, M. (1999). "Influence of key parameters on drying shrinkage of cementitious materials." Cem. Concr. Res., 29(10), 16551662.

[11]Naito, C.J., Parent, G., Brunn, G., 2006. "Performance of bulb-tee girders made with self-consolidating concrete". PCI Journal, 51(6):72-85.

[12]Gilson Lomboy, Kejin Wang, M.ASCE, and Chengsheng Ouyang (2011). "Shrinkage and Fracture properties of Self-Consolidating Concrete" Journal of Materials in Civil Engineering (J. Mater. Civ. Eng. 2011.23:1514-1524).

[13]Carlson RW, Reading TJ. "Model study of shrinkage cracking in concrete building walls". ACI Struct J 1988;85(4):395-404.

[14]Wiegrink K, Marikunte S, Shah P. "Shrinkage cracking of high strength concrete". ACI Mater J 1996;93(5):409-15.

[15] Persson, P. _1999_. "Creep, shrinkage and elastic modulus of selfcompacting concrete." Proc., 1st Int. RILEM Symp. on Self- Compacting Concrete, Stockholm, Sweden, 239-250.

[16]Klug, Y., and Holschemacher, K. 2003_. "Comparison of the hardened properties of self-compacting and normal vibrated concrete." Proc. 3rd Int. RILEM Symp. on SelfCompacting Concrete, Reykjavik, Iceland, 596-605.

[17]Weiss J, Berke N. Shrinkage reducing admixtures; in early age cracking in cementitious systems. Report of RILEM Technical Committee 181-EAS, Early age shrinkage induced stresses and cracking in cementitious systems: RILEM Publications SARL; 2002.

[18] Farhad ASLANI , Shami NEJADI. "Shrinkage behavior of Self Compacting Concrete" (2012). Aslani et al. / J Zhejiang Univ-Sci A (Appl Phys \& Eng) 2012 13(6):407419. Journal of Zhejiang University-SCIENCE A (Applied Physics \& Engineering).

[19]Scandiuzzi L, Battagin AF. A "Utilização da escória granulada de altofornocomo agregado miúdo". Estudo Técnico n_ 95. Associação Brasileira de Cimento Portland, São Paulo; 1990.

[20]Topçu IB, Bilir T. "Effect of non-ground-granulated blast-furnace slag as fine aggregate on shrinkage cracking of mortars". ACI Mater J 2010;107(6):545-53. 
[21]Aïtcin PC. "Demystifying autogenous shrinkage". Concr Int 1999;21(11):54 6.

[22]Saito K, Kinoshita M, Umehara H, Yoshida R. "Properties of low-shrinkage, high strength SCC using shrinkage-reducing admixture, blast furnace slag and limestone aggregates". In: Khayat KH, Feys D, editors. Design, production and placement of self-consolidating concrete, RILEM Bookseries 1; 2010. p. 283-93.

[23]Arellano R, Burciaga O, Escalante JI. "Lightweight concretes of activated metakaolin-fly ash binders, with blast furnace slag aggregates". Constr Build

Mater 2010;24:1166-75.

[24]M.Valcuende, F. Benito, C. Parra , I. Miñano. "Shrinkage of Self compacting concrete with blast furnace slag as fine aggregate". Construction and Building Materials 76 (2015) 1-9.

[25]Brooks JJ, Cabrera JG, Megat MA. "Factors affecting the autogenous shrinkage of silica fume high-strength concrete". In: Tazawa E, editor. Autogenous shrinkage of concrete. Taylor \& Francis; 1999. p. 195-202.

[26]Valcuende M, Marco E, Parra C, Serna P. "Influence of limestone filler and viscosity-modifying admixture on the shrinkage of self-compacting concrete". Cem Concr Res 2012;42(4):583-92

[27]Rozière E, Granger S, Turcry P, Loukili A. "Influence of paste volume on shrinkage cracking and fracture properties of self-compacting concrete". Cem Concr Compos 2007;29(8):626-36.

[28]Loser R, Leemann A. "Shrinkage and restrained shrinkage cracking of self compacting concrete compared to conventionally vibrated concrete". Mater Struct 2009;42(1):71-82.

[29] G. Heirman, L. Vandewalle, D. Van Gemert, "Influence of Mineral Additions and Chemical Admixtures on Setting and Volumetric Autogenous Shrinkage of SCC Equivalent- Mortars", in: G. De Schutter, V. Boel (Eds.), Proceedings of $5^{\text {th }}$ international RILEM symposium on selfcompacting concrete, RILEM Publications S.A.R.L., Ghent, 2007, pp. 553-558.

[30] B. Lothenbach, G. Le Saout, E. Gallucci, K. Scrivener, "Influence of limestone on the hydration of Portland cements", Cem. Concr. Res. 38 (6) (2008) 848-860.

[31]M.Valcuende, E.Marco, C.Parra, P.Serna. "Influence of limestone filler and viscosity-modifying admixture on the shrinkage of self-compacting concrete". Cement and Concrete Research 42 (2012) 583-592.

[32]C. Legrand, E. Wirkin, "Study of the strength of very young concrete as a function of the amount of hydrates formed - influence of superplasticizer", Mater. Struct. 27 (2) (1994) 106-109.

[33]Collepardi M, Borsoi A, Collepardi S, Ogoumah Olagot JJ, Troli R. Effects of shrinkage-reducing admixture in shrinkage compensating concrete under non wet curing conditions. Cem Concr Compos 2005;27(6):704-8.

[34]Valeria Corinaldesi. "Combined effect of expansive, shrinkage reducing and hydrophobic admixtures for durable self compacting concrete". Construction and Building Materials 36 (2012) 758-764. 